\title{
Disorders of Major Inflammatory Factors and Histopathological Lesions in Excess-iron-fed Sheep Liver
}

\section{LiangYu Zhang}

Northeast Agricultural University

Jing Lu

Northeast Agricultural University

FengJiao Sun

Northeast Agricultural University

XiaoPing Lv

Northeast Agricultural University

ChaoNan Liu

Northeast Agricultural University

XueLi Gao ( $\nabla$ gaoxueli@neau.edu.cn )

Northeast Agricultural University

\section{Research Article}

Keywords: excess iron, sheep, liver, inflammatory factors, histopathological changes

Posted Date: May 13th, 2021

DOI: https://doi.org/10.21203/rs.3.rs-498884/v1

License: () (1) This work is licensed under a Creative Commons Attribution 4.0 International License. Read Full License 


\section{Abstract}

Background: Iron plays a key role in biological metabolism as an essential microelement. Excess iron may cause pathological damage to the body. The purpose of this work is to explore the disorders of major inflammatory factors and histopathological lesions in the liver of excess-iron-fed sheep. Twenty German Mutton Merino sheep were randomly divided into 4 groups, control group (CON), iron-excess group one (IronE1), iron-excess group two (IronE2) and iron-excess group three (IronE3), respectively. Each group was fed with basal diets supplemented with 50 (CON), 500 (IronE1), 1000 (IronE2), and 1500 (IronE3) $\mathrm{mg} / \mathrm{kg}$ as ferrous sulfate monohydrate $\left(\mathrm{FeSO}_{4} \cdot \mathrm{H}_{2} \mathrm{O}\right)$. After 75 days, the liver was removed and collected. A variety of methods were utilized to detect indicators of sheep liver.

Results: The histopathological damage of liver in sheep was rather severe with the excess of iron. Hemosiderin deposits were also obviously discovered. The results also showed that the expression of both protein and mRNA of IL-1 $\beta$, TNF- $\alpha$ and IFN- $\gamma$ reduced, but the factors of IL-2, IL-6, NF-KB and TGF- $\beta 1$ obviously increased in the liver of each iron excess group. Corresponding changes were also discovered with the addition of iron dosage. The content of inflammatory factors above showed a significant change with an addition of $1500 \mathrm{mg} / \mathrm{kg}$ iron into the basic diet, which indicated that excess iron inhibited the release of IL-1 $\beta$, TNF- $\alpha$ and IFN- $\gamma$ in the sheep liver. The inflammation caused by excess iron extenuated by reducing the content of these three pro-inflammatory factors. The expression of IL-2, IL-6, NF-KB and TGF- $\beta 1$ increased. As pro-inflammatory factors induced inflammation, anti-inflammatory factors also increased to protect the body from tissue damage.

Conclusions: It can be concluded that excess iron can change the expression of main inflammatory factors in sheep liver, which will be an instructive significance to the development of medical prospect for sheep breeding and disease diagnosis.

\section{Introduction}

As a basic trace element in the organism, iron is involved in various biological reactions, including blood oxygen transport of snow globulin, myoglobin synthesis, energy metabolism, DNA synthesis, and various enzyme reactions[1-4]. It also participates in the activation and regulation of immune system, and the proliferation and differentiation of immune cells[5]. According to the research announced by National Research Council (NRC), sheep has the least tolerance to iron compared with other livestock[6].The risk of toxicosis will increase if maximum dose of iron is provided[7]. Iron is transported to all parts of the body via blood circulation and widely distributed in sorts of tissues and organs[8].Therefore, excess iron will cause renal anemia, liver disease, cardiovascular disease, and nerve damage. It can also increase the susceptibility of certain viruses and bacteria[2, 9]. It has been found that impaired iron metabolism is related to many liver diseases, especially non-alcoholic fatty liver and acute or chronic liver failure[10]. It is of vital importance to maintain iron homeostasis in cells, which is the key to cell survival. Oxidative stress and mitochondrial dysfunction are considered to be important targets of various physiological and pathological processes to the damage of excess iron to the body[11, 12]. When excess iron is exceeded, 
organs in the body would mainly deposit in the liver, spleen, kidney, and bone marrow Krill oil alleviates oxidative stress, iron accumulation and fibrosis in the liver and spleen of iron-overload rats[11, 13, 14]. Besides, abnormal accumulation of iron can cause damage to organs, tissue systems and metabolic disorders[15].

Liver is one of the key organs of the body and regulates the metabolism of carbohydrates, lipids, and proteins. It is also the center for biotransformation and detoxification of endogenous metabolites[11]. It plays an important role in synthesis and secretion of bile salts, the absorption of bile salt-dependent nutrients, and the secretion of metabolites, innate immunity and adaptive immunity included[12]. The liver affects the process of iron metabolism[16]. A variety of iron-related proteins are regulated and expressed in the liver, such as hepcidin[17, 18]. It has been reported that chronic iron intake significantly increases the iron content of the liver, causing oxidative stress[13]. Oxidative stress affected by excess iron in liver cells or Kupffer cells promotes the liver damage. A treatment strategy has been obtained for chronic liver disease by controlling iron homeostasis[19].

The relationship between iron and immune function has been concerned, particularly in related to the underlying inflammatory process found in diseases with chronic immune stimulation[17, 20]. The skeletal muscle produces and releases IL-6, which can increase the concentration of blood hepcidin[7]. P. Huang has found that IL- 6 and TNF-a can promote hepcidin for accelerating iron metabolic homeostasis and improve the expression of TfR224. They can be inhibited by IL-10 to down-regulate hepcidin. The expression of STAT3 can be suppressed, then improving iron metabolic homeostasis and inflammatory anemia symptoms[1]. Iron storage can be promoted in monocytes/macrophages by increasing the expression of inflammatory factors. Hepcidin affects iron homeostasis, leading to iron excess or iron deficiency in macrophages under different conditions $[7,8]$.

The aim of this essay is to state the influence on the sheep liver with excess iron in the diet, affiliated by major inflammatory factors and histopathological changes. After establishing animal models with different doses of excess iron treatment, major inflammatory factors in the liver of sheep (IL-1 $\beta$, IL-2, IL-6, TNF- $a$, IFN- $\gamma$, TGF- $\beta 1$ ) and NF-KB content are attempted to be detected and tissue pathological changes are required to be observed, which will provide theoretical basis for studying the toxic mechanism of excess iron and the rational application of iron in sheep feeding and management.

\section{Materials And Methods}

\section{Animals and Treatments}

Twenty eight-month-old German Mutton Merinorams, weighing approximately $43 \mathrm{~kg}$ (Institute of Animal Science, Academy of Agriculture Science of Heilongjiang Province, China) were used in the study. All the sheep were randomly divided into four groups: control group (CON), iron-excess group one (IronE1), ironexcess group two (IronE2), and iron-excess group three (IronE3), with five animals each. Supplemental iron of $50,500,1000$, and $1500 \mathrm{mg} / \mathrm{kg}$ (in the form of $\mathrm{FeSO}_{4} \cdot \mathrm{H}_{2} \mathrm{O}$ ) was respectively added into the four 
groups. All the sheep were dewormed and vaccinated, reared in individual pens, available to water ad libitum and fed twice a day at dawn and dusk. No expected or unexpected adverse events happened. After keeping for 75 days, all the animals of the four groups were bled to death after given a certain dose of anesthesia without any pain according to the welfare regulations of experimental animals. The liver was taken immediately and stored at $-80^{\circ} \mathrm{C}$ for the following operations, and the remaining samples were fixed with $10 \%$ formalin and submitted to routine hematoxylin-eosin (HE) staining.

\section{Real-time Quantitative PCR (qPCR) to detect of inflammatory factors mRNA Expression}

Total RNA was extracted from the liver of sheep using Trizol extraction method, and CDNA was synthesized from $1 \mu \mathrm{g}$ of RNA using iScript cDNA synthesis kit (Bio-Rad, USA). The primers sequences and amplification fragments sizes of gene for $\beta$-actin ( For.: AGATGTGGATCAGCAAGCAG; Rev.: CCAATCTCATCTCGTTTTCTG), IL-1 $\beta$ (For.: GGAGAATGTGGTGATGGTGACAGC; Rev.: ATTGGCAATGGCTTCCAGGTCATC), IL-2 (For.: GCACTAACTCTTGCACTCGTTGC; Rev.: GCATCCTGGAGAGCTTGAGGTTC), IL-6 (For.: ACACTGACATGCTGGAGAAGATGC; Rev.: GCCGCAGCTACTTCATCCGAATAG), TNF-a (For:: CTGGTGCCTCAGCCTCTTCT; Rev.: GGGACTGCTCTTCCCTCTGG), IFN-ץ (For.: AAGTTCTTGAACGGCAGCTCTGAG; Rev.: TTGGCGACAGGTCATTCATCACC), NF-kB (For:: TCGAGGTTCGGTTCTACGAGGATG; Rev.: AACACGGTTACAGGACGCTCAATC), and TGF- $\beta 1$ (For:: ACTACTACGCCAAGGAGGTCACC; Rev. : CACAGGTTCAGGCACTGCTTCC) were designed using Oligo Primer Analysis Software (Version 7.0, Oligo $($ ) according to the genomic and CDNA sequences of sheep and synthesized by Sangon Biotech (Shanghai, China). Quantitative qPCR was performed on a Roche LightCycler 480II System (Roche, Switzerland) in a $20 \mu \mathrm{L}$ reaction. PCR was performed with the following protocol: $95^{\circ} \mathrm{C}$ for $2 \mathrm{~min}, 46$ cycles of $95^{\circ} \mathrm{C}$ for $10 \mathrm{~s}$, annealing at $58.7^{\circ} \mathrm{C}$ for $30 \mathrm{~s}$, extension $72^{\circ} \mathrm{C}$ for $15 \mathrm{~s}$. Fluorescence signal was detected during annealing extension. $\beta$-actin was used as an internal reference control. Experiments repeated, the $2^{-\Delta \Delta C t}$ method was used for calculation and analysis.

\section{Western Blotting to examine NF-KB and TGF- $\beta 1$ protein expression}

The sample was extracted $0.050 \mathrm{~g}$ using RIPA Lysis buffer supplemented with protease inhibitor on ice, then centrifuged at a high speed of $12,000 \mathrm{rpm}$ at $4^{\circ} \mathrm{C}$ for $20 \mathrm{~min}$. Protein concentration was tested following the BCA protein assay regarding BSA as a standard to adjust the concentration consistent. The protein was mixed with $5 \times$ SDS PAGE loading buffer at 4 times the volume of the protein solution. The protein lysate was added to a $15 \%$ SDS polyacrylamide gel after the bath was heat-denatured and proteins were electro-transferred onto a NC membrane (Biotopped, China). Membranes were blocked with $10 \%$ skimmed milk for $2 \mathrm{~h}$ and incubated with primary antibodies rabbit anti-GPx1 (Bioss, China) and mouse anti- $\beta$-actin mAb (Zisbio, China) over-night. After washing, the membranes were incubated with secondary horseradish-conjugated anti-rabbit and anti- mouse (Zisbio) antibodies and detected by ECL system (NCM Biotech, China). 


\section{Measurement of IL-1 $\beta \square I L-2 \square I L-6 \square T N F-a$ and IFN- $\gamma$ by using ELISA}

The sample was extracted $0.050 \mathrm{~g}$ with diluent (PBS PH 7.4) at a weight-to-volume ratio of $1 \mathrm{~g}: 9 \mathrm{~mL}$, lowtemperature grinding and centrifugation. The levels of IL-1 $\beta$, IL-2, IL-6, TNF- $\alpha$ and IFN- $\gamma$ in the supernatant were determined using an enzyme-linked immunosorbent assay (ELISA) kit according to the manufacturer's instructions (R\&D Systems, Minneapolis, MN, USA).

\section{Hematoxylin-Eosin (HE) and Perl Staining for pathological examination}

The sections were prepared by frozen section method. Tissues were cautiously fixed and embedded with the embedding agent, frozen for 10 minutes, and then sectioned. Serial sections were taken for $\mathrm{HE}$ staining.

Basic operation methods of HE staining were as follows: Sections were deparaffinized in xylene $(2 \times 6$ min) and rehydrated by continuous washing in $100 \%, 95 \%, 90 \%, 80 \%$, and $70 \%$ ethanol. They were then stained with hematoxylin (30 s), rinsed with distilled water, rinsed with $0.1 \%$ hydrochloric acid in $75 \%$ ethanol, rinsed with tap water for $10 \mathrm{~min}$, stained with eosin for $5 \mathrm{~min}$, and rinsed again with distilled water. The slides were then dehydrated with $95 \%$ and $100 \%$ ethanol, dehydrated with xylene $(2 \times 4$ min), and mounted with coverslips using cedar wood oil.

Prussian blue dye solution was prepared before staining according to the instruction. Only few differences exist between the steps of two staining. Sections were stained with nuclear fast red for 510 min and rehydrated by continuous washing in $100 \%, 95 \%, 90 \%, 80 \%$, and $70 \%$ ethanol after rinsing with distilled water (5s).

\section{Statistical Analysis}

All the experimental data was analyzed by SPSS 17.0 software to interpret the differences between the groups, and GraphPad Prism 8.0 software was used to analyze the result. All the data was expressed in the form of "mean \pm standard deviation".

\section{Results}

\section{mRNA expression of inflammatory factors in the liver of excess-iron-fed sheep}

As is shown in Table 1, The expression of IL-1 $\beta$, TNF- $a$, IFN- $y$ of mRNA in sheep liver all decreased with the addition of iron. The expression of TNF- $\alpha$ in each IronE group was significantly lower than that of the control group ( $p<0.05, p<0.01)$, respectively. The mRNA expression of IL-1 $\beta$ and IFN- $\gamma$ in IronE2 and IronE3 was significantly or extremely significantly lower than the control group and IronE1 $(p<0.05$ or $p<$ 
$0.01)$, IronE3 was significantly or extremely significantly lower than IronE2 $(p<0.05$ or $p<0.01)$, and IronE1 was not significantly different than that of the control group.

The mRNA expression of IL-2, IL-6, NF-KB, and TGF- $\beta 1$ all increased with the reduction of iron. IL-2 and IL6 in each iron excess group expressed significantly or extremely more highly than that of the control group ( $p<0.05$ or $p<0.01)$. IronE2 was significantly or extremely higher than IronE1 $(p<0.05$ or $p<0.01)$, while IronE3 varied equally to the both above $(p<0.05$ or $p<0.01)$. NF-KB and TGF in IronE2 and IronE3 were higher than that of the control group $(p<0.05$ or $p<0.01)$. All in IronE1 varied less and obviously lower than the other two groups $(p<0.05$ or $p<0.01)$. (Fig. 1)

Table 1

Changes of mRNA expression of inflammatory factors in sheep liver with iron excess

\begin{tabular}{|c|c|c|c|c|}
\hline $\begin{array}{l}\text { Inflammatory factors } \\
\text { /Groups }\end{array}$ & CON & IronE1 & IronE2 & IronE3 \\
\hline IL-1 $\beta$ & $1.00 \pm 0.000$ & $0.95 \pm 0.025$ & $0.88 \pm 0.029^{*}$ & $0.20 \pm 0.001^{* *}$ \\
\hline TNF-a & $1.00 \pm 0.000$ & $0.90 \pm 0.078^{*}$ & $0.62 \pm 0.050^{\star}$ & $0.16 \pm 0.040^{* \star}$ \\
\hline IFN-y & $1.00 \pm 0.000$ & $0.96 \pm 0.047$ & $0.78 \pm 0.014^{\star}$ & $0.55 \pm 0.070^{\star *}$ \\
\hline IL-2 & $1.00 \pm 0.000$ & $24.50 \pm 0.111^{\star *}$ & $27.57 \pm 0.518^{\star \star}$ & $32.11 \pm 0.006^{\star \star}$ \\
\hline IL-6 & $1.00 \pm 0.000$ & $10.3 \pm 0.651^{*}$ & $27.83 \pm 1.616^{\star \star}$ & $62.03 \pm 1.165^{\star \star}$ \\
\hline NF-KB & $1.00 \pm 0.000$ & $1.36 \pm 0.518$ & $10.02 \pm 0.100^{\star \star}$ & $17.21 \pm 0.232^{\star \star}$ \\
\hline TGF- $\beta 1$ & $1.00 \pm 0.000$ & $1.27 \pm 0.124$ & $2.16 \pm 0.524^{*}$ & $3.85 \pm 0.142^{\star \star}$ \\
\hline
\end{tabular}

Compared with the control group,the values with asterisk differ significantly(with single asterisk, $\mathrm{p} \otimes 0.05$ ) or extremely significantly(with double asterisk, $\mathrm{p} \llbracket 0.01$ ), and no significantly (with no asterisk $₫ \mathrm{p} \llbracket 0.05$ ).

Figure 1 The changes of inflammatory factors mRNA expression. Data is expressed as mean \pm SD of independent experiments performed in triplicate. Compared with the control group, the asterisk means $p<$ 0.05 , double asterisks mean $\mathrm{p}<0.01$.

\section{Changes of inflammatory factor protein content in the liver of excess iron-fed sheep}

The protein content of IL-1 $\beta$, TNF- $\alpha$ and IFN- $\gamma$ in sheep liver decreased with the addition of iron(Table 2). A significant or extremely significant reduction of IL-1 $\beta$ was observed in IronE2 and IronE3 compared with the control group and IronE1 ( $p<0.05$ or $p<0.01$ ); The protein content of both IFN- $y$ and TNF- $a$ of IronE2 and IronE3 was significantly or extremely significantly lower than the control group $(p<0.05$ or $p<0.01)$, but just significantly lower than IronE1 $(p<0.05)$. All the three inflammatory factors in IronE3 were significantly lower than that of IronE2 ( $p<0.05)$ (Fig. 2$)$. 
The protein content of IL-2, IL-6, NF-KB and TGF- $\beta 1$ in the liver all increased with the addition of excess iron (TABLE2) (Table 3). The content of IL-2 in IronE1 was obviously higher than that in the control group $(p<0.05)$, and of which in IronE2 and IronE3 was significantly or extremely significantly higher than the control group ( $p<0.05$ or $p<0.01$ ). No obvious changes of IL-6 were found in IronE2 and IronE3(Fig. 2) (Fig. 3). The protein content of NF-KB in IronE2 and IL-2 in IronE3 were respectively significantly or extremely significantly higher than in the control group and IronE1. The NF-KB of IronE3 was significantly or extremely significantly higher than that of the control group $(p<0.05$ or $p<0.01)$, but no significant changes were found in IronE1 and IronE2. Besides, the protein content of TGF- $\beta 1$ in IronE2 and IronE3 was significantly or extremely significantly higher than in the control group $(p<0.05$ or $p<0.01)$. (Fig. 4)

Table 2

Changes of protein expression of inflammatory factors in sheep liver with iron excess

\begin{tabular}{|lllll|}
\hline $\begin{array}{l}\text { Inflammatory } \\
\text { factors } \\
\text { /Groups }\end{array}$ & CON & IronE1 & IronE2 & IronE3 \\
\hline IL-1 $\beta$ & & & & \\
\hline TNF-a & $322.67 \pm 35.303$ & $301.23 \pm 5.303$ & $211.54 \pm 8.839^{*}$ & $146.62 \pm 5.906^{* \star}$ \\
\hline IFN-Y & $752.71 \pm 4.553$ & $741.61 \pm 2.773$ & $726.37 \pm$ & $611.42 \pm 7.425^{\star *}$ \\
& & & $29.161^{*}$ & \\
\hline IL-2 & $530.58 \pm 13.954$ & $518.64 \pm 28.614$ & $456.16 \pm$ & $387.33 \pm$ \\
& & & $19.743^{*}$ & $22.052^{\star \star}$ \\
\hline IL-6 & $300.30 \pm 10.389$ & $350.36 \pm 7.129^{*}$ & $389.97 \pm$ & $424.84 \pm 3.565^{\star \star}$ \\
& $1308.50 \pm$ & $1392.44 \pm$ & $1508.88 \pm$ & $1886.00 \pm$ \\
\hline
\end{tabular}

Table 3

Changes of protein expression of inflammatory factors in sheep liver with iron excess(Gray value ratio)

\begin{tabular}{|lllll|}
\hline $\begin{array}{l}\text { Inflammatory factors } \\
\text { /Groups }\end{array}$ & CON & IronE1 & IronE2 & IronE3 \\
\hline NF-KB & & & & \\
\hline TGF- $\beta 1$ & $1.13 \pm 0.020$ & $1.26 \pm 0.105$ & $1.31 \pm 0.063^{*}$ & $1.35 \pm 0.113^{*}$ \\
\hline
\end{tabular}

\section{Pathological changes in sheep liver with excess-iron feeding}


We could observe that the structure of hepatic lobule was damaged and hard to distinguish with different degrees of connective tissue hyperplasia in iron-excess groups under a 100-fold microscope (Fig. 5). Obvious phenomenon such as connective tissue hyperplasia and inflammatory cell infiltration iron was found in IronE2 and IronE3 with the same magnification as above. Liver cell degeneration and necrosis were easily found. Cells changed significantly around the liver lobule. Brown-yellow hemosiderin particles were observed in some part of the perilobular liver cells in IronE3(Fig. 6).

\section{Distribution of hemosiderin in sheep liver after excess-iron feeding}

Hepatic hemosiderin was distributed in peripheral parts of hepatic lobules, spreading into lobules and gradually decreasing, mainly in hepatocytes and a small amount of reticuloendothelial tissue. Hemosiderin existed in IronE2 and IronE3 increasing with the overdose of iron. Besides, less hemosiderin could be seen in IronE3(Fig. 7).

\section{Discussion}

Liver is one of the largest organs with diverse functions in the body, which plays vital roles in detoxification of xenobiotics, digestion, synthesis of plasma proteins, gluconeogenesis, lipid metabolism, and storage[21]. Iron is the basic element of hemoglobin, some non-heme protein and certain enzymes, and has important physiological functions. As an essential mental element, iron is also stored in the liver. Cytokines involved in inflammatory response are inflammatory factors[22]. Proinflammatory factors can promote autoimmune response and anti-inflammatory factors alleviate inflammation and facilitate tissue repair[23]. The interaction of the two helps control inflammation, which is the key to the stability of microenvironment[24].

\section{Effect of excess iron on pathological changes of sheep liver}

Hemosiderin was obviously distributed in the liver stained with Prussian blue, mainly deposited in the periphery of the liver lobules after the sheep was given excess iron[25]. Studies have shown that elevated iron in liver is accompanied by significant fibrosis. Iron also participated in stimulating the induction of stellate cells, which then transformed into myofibroblasts[26]. We observed connective tissue hyperplasia in liver of IronE groups, especially in the peripheral part of liver lobules. Connective tissue hyperplasia and inflammatory cell infiltration could be seen obviously in the portal area of the iron in IronE2 and IronE3. In the meanwhile, Hemosiderin covered significantly in some of the hepatocytes of perilobules in IronE3, which further indicated that hemosiderin was mainly distributed in the periphery of the liver lobules.

\section{Effects of heavy metals administrated in the liver}

A variety of researches have shown that excessive or metal poisoning of heavy metals such as iron may cause damage to the function of liver, along with pathological changes. Fordahl $\mathrm{S}$ and his team examined the liver of weaned SD rats which were exposed to hydromanganese $(1 \mathrm{~g} \mathrm{Mn} / \mathrm{L})$ for six weeks, 
proved that hydromanganese exposure altered liver metabolites[27]. It has been found that specific enzymes in the mitochondrial matrix of liver would increase if excessive $\mathrm{Cr}(\mathrm{VI})$ was available to the body, which indicated that $\mathrm{Cr}$ could destroy the mitochondria of liver cells, making enzyme to be released in large quantities[28].Besides, rats exposed to aluminum generated degeneration of hepatocytes, dilated and congested hepatic sinuses, and disordered the arrangement of hepatocytes, along with focal necrosis, and hyperplasia of fibrous tissue[29] [30]. Parts of pro-inflammatory factors can regulate the expression of iron transport and protein storage. For instance, TNF-a can affect the level of hepcidin via $\mathrm{Hjv/BMP/Smad} \mathrm{pathway[31];} \mathrm{The} \mathrm{autocrine} \mathrm{circuit} \mathrm{among} \mathrm{IL-2} \mathrm{and} \mathrm{transferrin} \mathrm{and} \mathrm{its} \mathrm{receptor} \mathrm{involves}$ the proliferation of lymphocytes[32]; IL-1 $\beta$ has an influence on iron homeostasis by affecting the binding of iron regulatory protein and iron response elements[33].

\section{Effect of excess iron on pro-inflammatory factors in sheep liver}

In this experiment, the expression of both mRNA and protein of IL-1 3 , TNF- $\alpha$ and IFN- $\gamma$ decreased and the content of IL-2 and IL- 6 increased in the liver after excess iron was fed with. The change in expression corresponded to the dose of excess iron. The content of the inflammatory factors mentioned above showed significant or extremely significant changes ( $p<0.05$ or $p<0.01$ ), indicating that excess iron can affect the release of pro-inflammatory factors, and even cause less damage to the body. IL-1 $\beta$ functionates in inflammation and autoimmune diseases. It can participate in immune regulation and induce inflammation at a low concentration[34]. In this experiment, the decrease of IL-1 $\beta$ in sheep liver indicated that excess iron can inhibit the expression and release of IL-1 3 , and low-expressed IL-1 $\beta$ may play a role in stimulating immune regulation and inflammation. However, some study found an opposite perspective in alveolar cells[35]. And the reason for the difference is not clear, so further investigation would be conducted. Iron can inhibit the activity of IFN-y through macrophages[9], so macrophages with excess iron reduce the ability to clear intracellular pathogen infections[36]. In this experiment, excess iron caused the reduction of IFN- $\gamma$ indicating that iron has a negative regulatory effect on IFN- $\gamma$. Iron can also inhibit the activity of $\mathrm{CD}^{+}[9]$, and massive production of TNF-a will result in immune imbalance. The increase in the concentration of iron with addition of TNF-a antagonists will damage Th1, promoting the proliferation of bacteria, viruses, and causing infection[37]. Excess iron reduced the expression of TNF-a. Down-regulation of TNF-a caused damage to Th1 and inhibited the release of IFN- - . IL-2, a cytokine that stimulates the proliferation of T cells[38], can increase the survival rate of activated $T$ cells and killing the activity of $\mathrm{CD}^{+}$. Researches have shown that the activity of $T$ lymphocytes can be stimulated by increasing the level of $\mathrm{IL}-2$, then prompt $\mathrm{CD} 4^{+}$and $\mathrm{CD} 8^{+}$to produce $\mathrm{IL}-2$, and continue to stimulate $\mathrm{T}$ lymphocytes in a positive feedback manner[39]. In this experiment, excess iron caused a significant or extremely significant increase in mRNA and protein expression of IL-2 in sheep liver $(p<0.05$ or $p<0.01)$, indicating that excess iron may activate $T$ lymphocytes by stimulating increased IL-2 synthesis, promote

inflammation, and promote tissue fibrosis under the synergistic action of other inflammatory factors. IL- 6 can promote the proliferation of inflammatory cells and induce the production of acute phase reactive protein (APP) [40], regarded as a multidirectional inflammatory factor leading to tissue damage and 
enhance local inflammation[41]. In this experiment, we found an increase on the expression of mRNA and protein of IL- 6 and tissue damage from the histopathological results, which indicated that excess iron could promote the IL- 6 expression and release. It has been pointed out that low concentration of TNF can stimulate macrophages to secrete IL- 6 and other inflammatory factors[42]. Therefore, the increase of IL- 6 with excess iron can also be affected by the reduction of TNF-a.

\section{Effect of excess iron on anti-inflammatory factors and NF- $K B$ in sheep liver}

TGF- $\beta 1$ is one of the key mediators which induce fibrosis and inflammation in various organs. Excess hydroxyl free radicals generated by iron may be a key factor in the regulation of TGF- $\beta 1$ and tissue fibrosis[25]. Iron is considered to be a key molecule in hepatic stellate cell activation and extral cellear memberma gene expression[19]. In this experiment, excess iron promoted the increase of TGF- $\beta 1$. It was the phenomenon that the liver expressed fibrosis,indicating that iron can directly activate TGF- $\beta$ signaling to promote fibrosis which can be alleviated by iron chelating agents, then inhibiting TGF- $\beta$ signaling and fibrosis formation[43].

As a nuclear transcription factor, the signal transduction mode of NF-KB is a coexistence of positive and negative feedback regulation under the influence of multiple factors[26]. NF-KB can be activated through a variety of ways,which was proved by the phenomenon that iron chelating agents attenuate the activation of NF-KB in Microglia with excess iron provided[44]. In this experiment, the mRNA and protein content of NF-KB in the liver increased with the addition of excess iron; IronE3 had an increasing significant or extremely significant trend compared with the control group $(p<0.05$ or $p<0.01)$, which indicated that excess iron can increase and stimulate the expression of NF-KB. The reduction of IL-1 $\beta$ and TNF-a has further confirmed that the activation of NF-KB was more directly or indirectly caused by excess iron, which in turn stimulated the expression of IL-2 and IL-6, indicating that the increase of which other factors may affect.

\section{Conclusion}

In the experiment, we found the content of IL-1 $\beta$, IFN- $\gamma$, and TNF- - decreased while the content of IL-2, IL6 , TGF- $\beta 1$, and NF-KB increased in the liver after the sheep was provided with excess iron, which was all corresponded to the dose of excess iron. It could be indicated that excess iron can change the expression and release of main inflammatory factors in sheep liver. The damage caused by excess iron to the body can be reduced through the regulation of inflammatory factors. Liver is one of the main organs for iron deposition. Pathological damage can be observed, including tissue fibrosis, cell necrosis, and inflammatory cell infiltration. All the findings will be significant to the development of the field of medical prospect for animal breeding and disease diagnosis.

\section{Declarations}




\section{Ethics approval and consent to participate:}

All experimental procedures complied with written informed owner's consent according to the criteria in Guide for the Care and Use of Laboratory animals of Northeast Agricultural University.An Ethic Commission comprising 3 veterinarians of the Pathophysiology Laboratory and a government veterinarian from the the Northeast Institute of Geography and Agricultural Ecology, Chinese Academy of Sciences, follow the Ministerial Decree No. 384 of the year 2008 on the executive by-law of the Federal Law No. 16 of the year 2007 concerning Animal Welfare. The welfare of all experimental animals and treatment of them conducted by the Pathophysiology Laboratory are reviewed and approved by Bioethics Committee of the Northeast Institute of Geography and Agroecology, Chinese Academy of Sciences, Harbin, China (Protocol No. 2017005). The sheep used in this experiment belong to Dr. HaiXia Sun, from the Northeast Institute of Geography and Agricultural Ecology, Chinese Academy of Sciences, who verbally approved this trial.

\section{Consent for publication:}

Not applicable

\section{Availability of data and materials:}

The datasets used and/or analysed during the current study available from the corresponding author on reasonable request.

\section{Competing interests:}

The authors declare that they do not have any conflicts or competing interest in connection with the work submitted.

\section{Funding:}

This work was supported by the National Natural Science Foundation of China (Grant No. 31372355).

\section{Authors' contributions:}

All authors reviewed the manuscript. LiangYu Zhang and Jing Lu wrote the main manuscript test. FengJiao Sun and XiaoPing Lv finished all the figures and ChaoNan Liu did all the tables of the result. XueLi Gao responsed for the whole manuscript checking. 


\section{Acknowledgments:}

We thank the members of the Pathophysiology Laboratory at the College of Veterinary Medicine, Northeast Agricultural University.We also appreciate

\section{References}

1. Huang, P., et al., Effects of IL-10 on iron metabolism in LPS-induced inflammatory mice via modulating hepcidin expression. eur rev med pharmacol sci, 2017.

2. Traoré, H.N. and D. Meyer, The effect of iron overload on in vitro HIV-1 infection. Journal of Clinical Virology, 2004. 31(supp-S1): p. 92-98.

3. Uberti, V.H., et al., Iron Overload Impairs Autophagy: Effects of Rapamycin in Ameliorating IronRelated Memory Deficits. 2020.

4. Picca, A., et al., Advanced Age Is Associated with Iron DyshoDr. HaiXia Sun from the Northeast Institute of Geography and Agricultural Ecology, Chinese Academy of Sciences. meostasis and Mitochondrial DNA Damage in Human Skeletal Muscle. Cells, 2019. 8(12): p. 1525.

5. Poljak-Blazi, M., et al., Acute immunomodulatory effects of iron polyisomaltosate in rats. Immunobiology, 2009. 214(2): p. 121-128.

6. Nutrition, C.O.A., Nutrient requirements of domestic animals. 5. Nutrient requirements of sheep. Nutrient Requirements of Domestic Animals.nutrient Requirements of Sheep, 1968.

7. Liu, X.J., et al., Effects of Different Doses of Excessive Iron in Diets on Oxidative Stress in Immune Organs of Sheep. Biological trace element research, 2020. 197(1).

8. Lee, J.K., et al., Iron accumulation promotes TACE-mediated TNF-a secretion and neurodegeneration in a mouse model of ALS. Neurobiology of Disease, 2015. 80.

9. Nairz, M., et al., Iron at the interface of immunity and infection. Frontiers in Pharmacology, 2014. 5: p. 152.

10. Tang, Y., et al., CCL2 is Upregulated by Decreased miR-122 Expression in Iron-Overload-Induced Hepatic Inflammation. Cellular Physiology and Biochemistry, 2017. 44(3): p. 870-883.

11. Pagani, A., et al., Hepcidin and Anemia: A Tight Relationship. other, 2019. 10.

12. Bhattacharyya, S., P.B. Pal, and P.C. Sil, A 35kD Phyllanthus niruri protein modulates iron mediated oxidative impairment to hepatocytes via the inhibition of ERKs, p38 MAPKs and activation of PI3k/Akt pathway. Food \& Chemical Toxicology, 2013. 56(Complete): p. 119-130.

13. Helal, M.G. and D.H. El-Kashef, Krill oil alleviates oxidative stress, iron accumulation and fibrosis in the liver and spleen of iron-overload rats. Environmental Science and Pollution Research, 2020. 27(4).

14. Rainey, N.E., et al., Iron chelation by curcumin suppresses both curcumin-induced autophagy and cell death together with iron overload neoplastic transformation. Cell Death Discovery. 
15. Ward, R.J., et al., Effects of marginal iron overload on iron homeostasis and immune function in alveolar macrophages isolated from pregnant and normal rats. BioMetals, 2009. 22(2): p. 211-223.

16. Sheikh, N., J. Dudas, and G. Ramadori, Changes of gene expression of iron regulatory proteins during turpentine oil-induced acute-phase response in the rat. Laboratory Investigation, 2007. 87(7): p. 71325.

17. Buyukyazi, G., et al., The effect of 8-week different-intensity walking exercises on serum hepcidin, IL6, and iron metabolism in pre-menopausal women. Physiology International, 2017. 104(1): p. 52-63.

18. Patti, M.C.B.D., et al., Interleukin-1 $\beta$ up-regulates iron efflux in rat $\mathrm{C} 6 \mathrm{glioma}$ cells through modulation of ceruloplasmin and ferroportin-1 synthesis. Neuroscience Letters, 2004. 363(2): p. 182-186.

19. Otogawa, K., et al., Attenuation of acute and chronic liver injury in rats by iron-deficient diet. American Journal of Physiology, 2008. 294(2): p. 311-320.

20. Weiss, G., Modification of iron regulation by the inflammatory response. Best Practice \& Research Clinical Haematology, 2005. 18(2): p. 183-201.

21. Rishi, G. and V.N. Subramaniam, The liver in regulation of iron homeostasis. Am J Physiol Gastrointest Liver Physiol, 2017: p. G157.

22. Duhen, T., et al., Production of interleukin 22 but not interleukin 17 by a subset of human skin-homing memory T cells. Nature Immunology, 2009. 10(8): p. 857.

23. NA, Cellular and Molecular Immunology, 7th Edition. Medicine \& Science in Sports \& Exercise, 2012. 44(5): p. 983.

24. Wang, X., et al., [Role and Significance of T Help Cells 17 in Pathogenesis of Idiopathic Thrombocytopenic Purpura]. Zhongguo Shi Yan Xue Ye Xue Za Zhi, 2016. 24(6): p. 1833.

25. Saito and K., Iron chelation and a free radical scavenger suppress angiotensin Il-induced upregulation of TGF- $\beta 1$ in the heart. Ajp Heart \& Circulatory Physiology, 2005. 288(4): p. H1836-43.

26. Guo, L., et al., Increased iron deposition in rat liver fibrosis induced by a high-dose injection of dimethylnitrosamine. Experimental \& Molecular Pathology, 2006. 81(3): p. 255-261.

27. Fordahl, S., et al., Waterborne manganese exposure alters plasma, brain, and liver metabolites accompanied by changes in stereotypic behaviors. Neurotoxicology \& Teratology, 2012. 34(1): p. 2736.

28. Borges, K.M. and K.E. Wetterhahn, Chromium bound to DNA alters cleavage by restriction endonucleases. Chemical Research in Toxicology, 1991. 4(6): p. 638-641.

29. Congli, et al., CysLTR1 blockage ameliorates liver injury caused by aluminum-overload via PI3K/AKT/mTOR-mediated autophagy activation in vivo and in vitro. Molecular Pharmaceutics, 2018.

30. Hui, et al., Treatment with either COX-2 inhibitor or 5-LOX inhibitor causes no compensation between COX-2 pathway and 5-LOX pathway in chronic aluminum overload-induced liver injury in rats. Fundamental \& clinical pharmacology, 2019. 
31. VM, K., et al., Tumor necrosis factor-alpha down-regulates human elastin gene expression. Evidence for the role of AP-1 in the suppression of promoter activity. Journal of Biological Chemistry, 1992. 267(36): p. 26134.

32. Lum, J.B., et al., Transferrin synthesis by inducer T lymphocytes. Journal of Clinical Investigation, 1986. 77(3): p. 841-9.

33. Wang, J., et al., Pro-inflammatory cytokines modulate iron regulatory protein 1 expression and iron transportation through reactive oxygen/nitrogen species production in ventral mesencephalic neurons. Biochimica Et Biophysica Acta, 2013. 1832(5): p. 618-625.

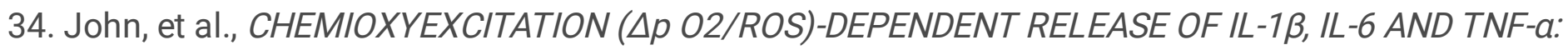
EVIDENCE OF CYTOKINES AS OXYGEN-SENSITIVE MEDIATORS IN THE ALVEOLAR EPITHELIUM. Cytokine, 2001.

35. O'brien-ladner, A.R., B.M. Blumer, and L.J. Wesselius, Differential regulation of human alveolar macrophage-derived interleukin-1 $\beta$ and tumor necrosis factor-a by iron. Journal of Laboratory and Clinical Medicine, 1998.

36. Oexle, H., et al., Pathways for the regulation of interferon-y-inducible genes by iron in human monocytic cells. Journal of Leukocyte Biology, 2003. 74(2).

37. Ghio, A.J. and E.D. Weinberg, Complications of TNF- $a$ antagonists and iron homeostasis. Medical Hypotheses, 2012. 78(1): p. 33-35.

38. Tohidi, R. and M.H. Bejo, The effects of polymorphisms in IL-2, IFN- $y$, TGF- $\beta 2$, IgL, TLR-4, MD-2, and iNOS genes on resistance to Salmonella Enteritidis in indigenous chickens. Avian Pathology Journal of the W.v.p.a, 2012. 41(6): p. 605-612.

39. Pourgheysari, B., et al., Low IL-2 Expressing T Cells in Thalassemia Major Patients: Is It Immune Aging. Indian Journal of Hematology \& Blood Transfusion, 2018. 34(2): p. 1-9.

40. Musolino, C., et al., Inflammatory and Anti-Inflammatory Equilibrium, Proliferative and Antiproliferative Balance: The Role of Cytokines in Multiple Myeloma. Mediators of Inflammation, 2017. 2017(5): p. 1-24.

41. Borkhsenius, S.N., O.A. Chernova, and V.M. Chernov, [Interaction of Mycoplasma with immune system of animals and humans]. tsitologiia, 2001. 43(3): p. 219-43.

42. Klee, S., et al., WISP1 mediates IL-6-dependent proliferation in primary human lung fibroblasts. Scientific Reports, 2016. 6: p. 20547.

43. Jarosz, U., et al., Effects of feed supplementation with glycine chelate and iron sulfate on selected parameters of cell-mediated immune response in broiler chickens. Research in Veterinary Science, 2016. 107: p. 68-74.

44. Zhang, X., et al., Cellular iron status influences the functional relationship between microglia and oligodendrocytes. Glia, 2010. 54(8): p. 795-804.

\section{Figures}




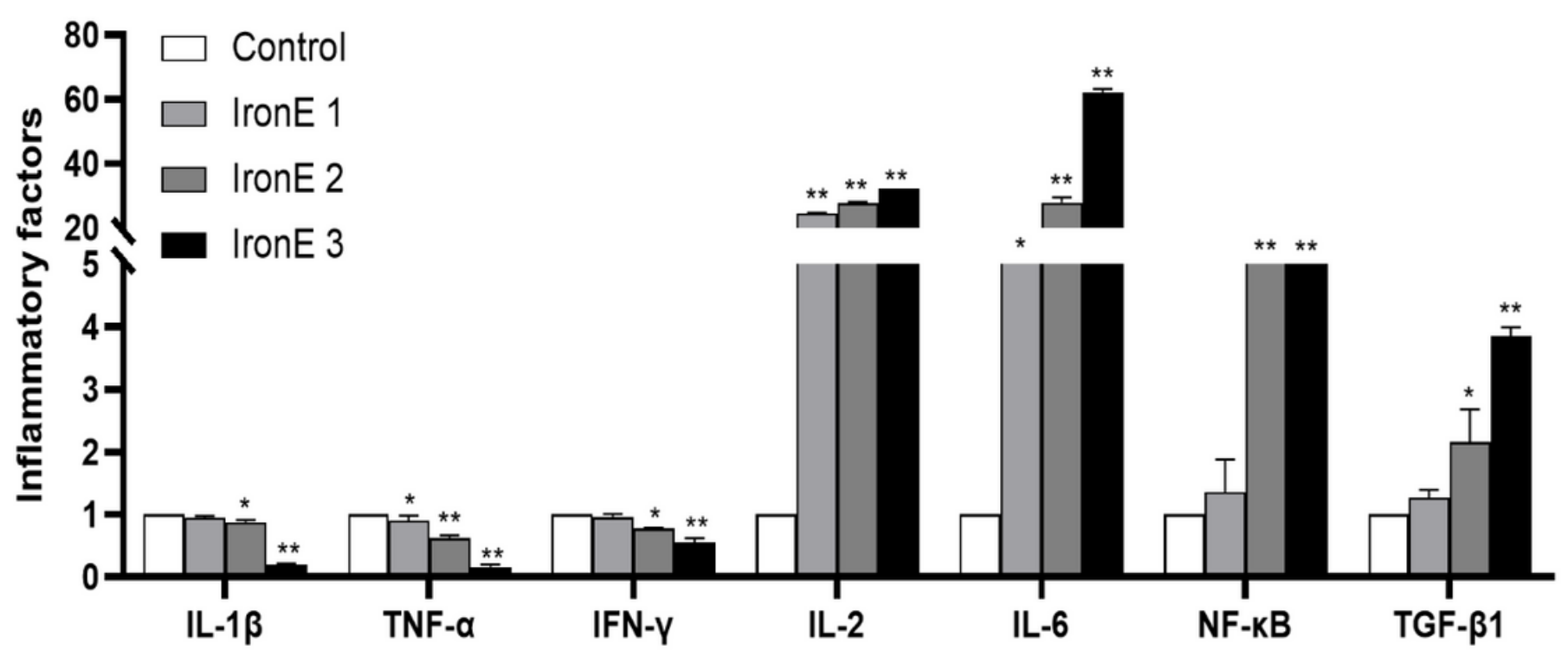

Figure 1

The changes of inflammatory factors mRNA expression. Data is expressed as mean \pm SD of independent experiments performed in triplicate. Compared with the control group, the asterisk means $p<0.05$, double asterisks mean $\mathrm{p}<0.01$.

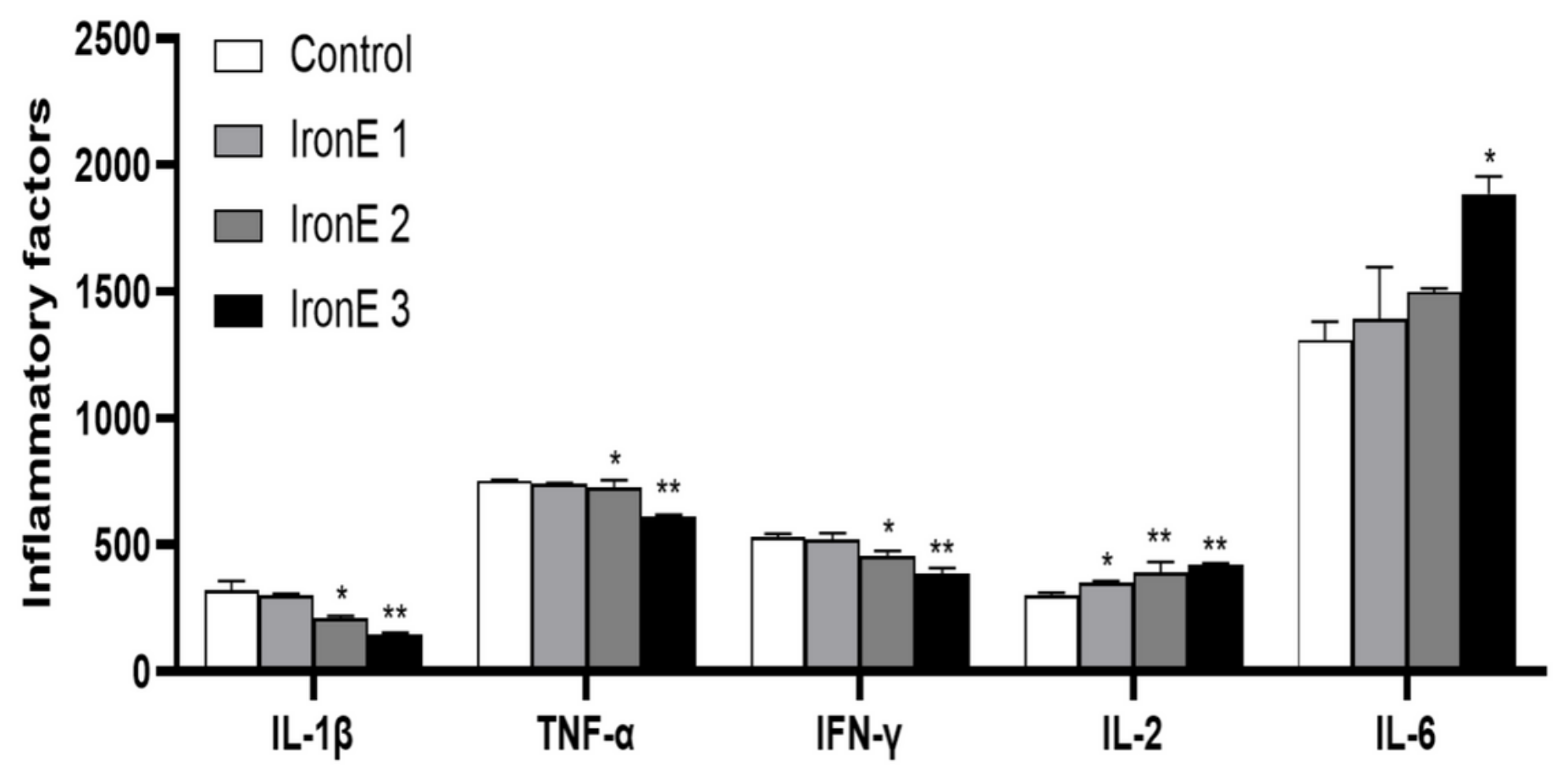

Figure 2

The changes of inflammatory factors protein expression. Data is expressed as mean \pm SD of independent experiments performed in triplicate. Compared with the control group, the asterisk means $p<0.05$, double asterisks mean $\mathrm{p}<0.01$. 


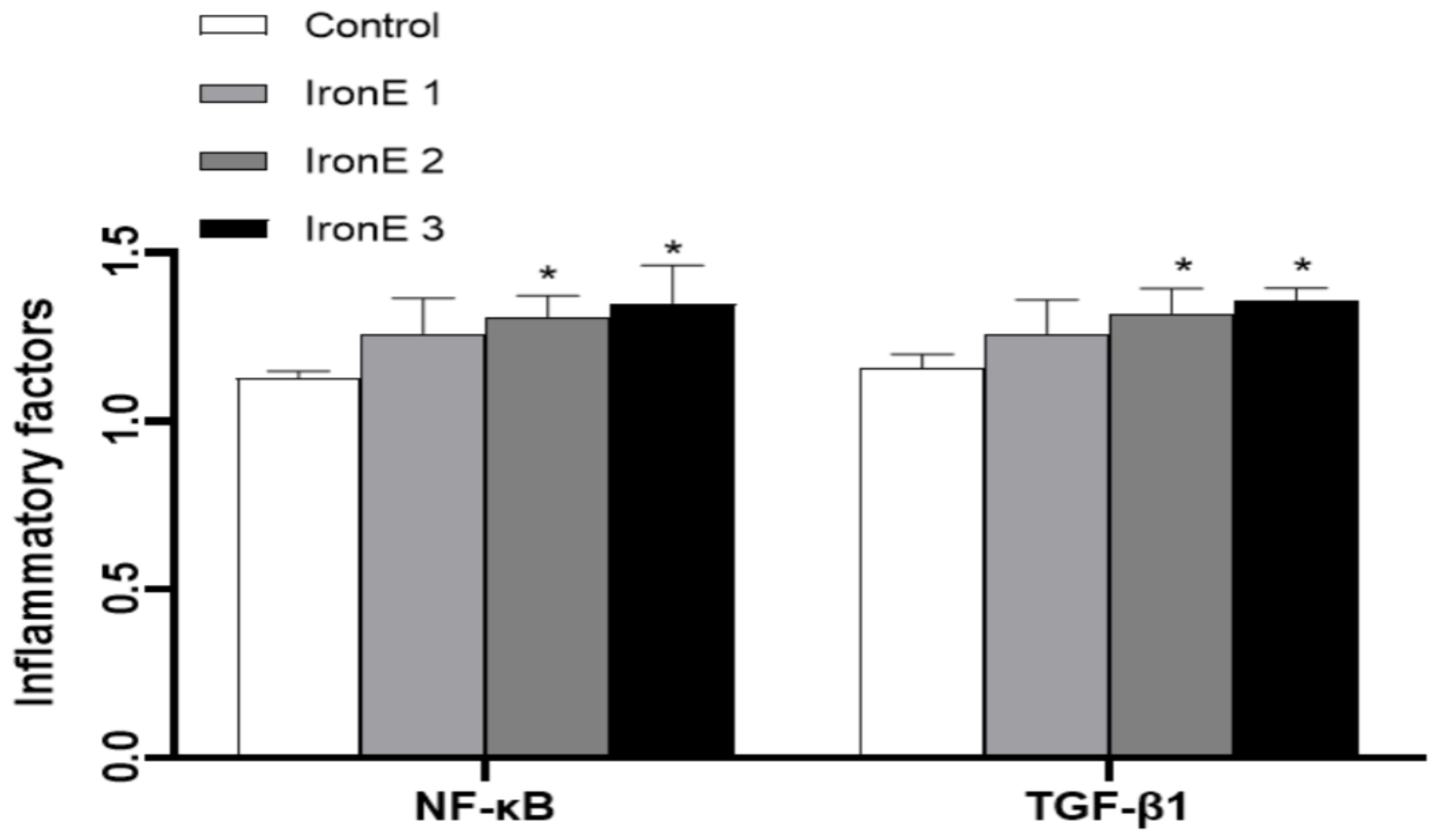

Figure 3

The changes of inflammatory factors protein expression(Gray value ratio). Data is expressed as mean \pm SD of independent experiments performed in triplicate. Compared with the control group, the asterisk means $p<0.05$, double asterisks mean $p<0.01$.

CON IronE1 IronE2 IronE3

$\beta$-actin

$\mathrm{NF}-\mathrm{kB}$

TGF- $\beta 1$

Figure 4

Changes of NF-KB,TGF- $\beta 1$ content in liver after iron excess in sheep 


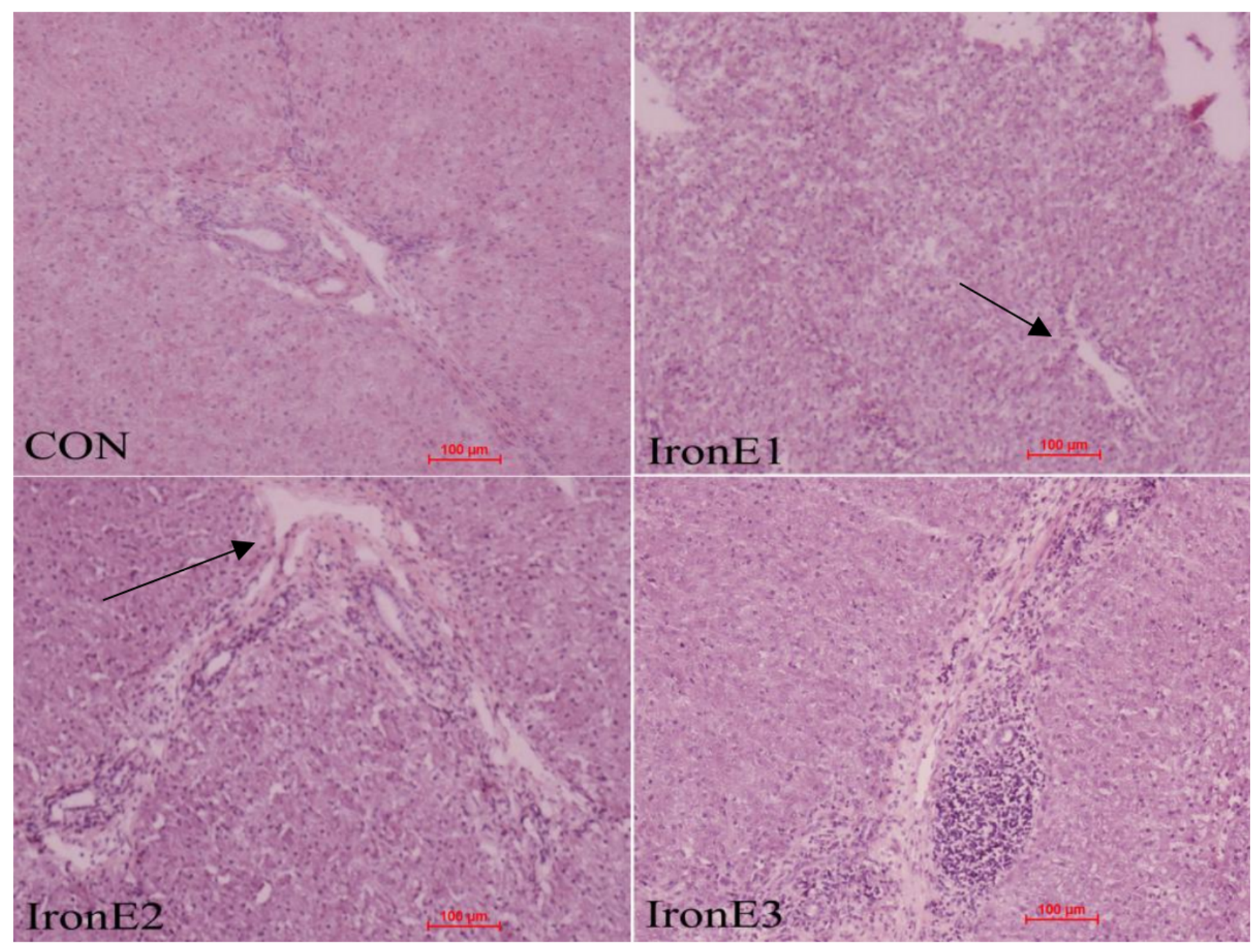

Figure 5

Histopathological disorders of liver with excess iron in sheep $(\mathrm{HE} \times 100)$ 


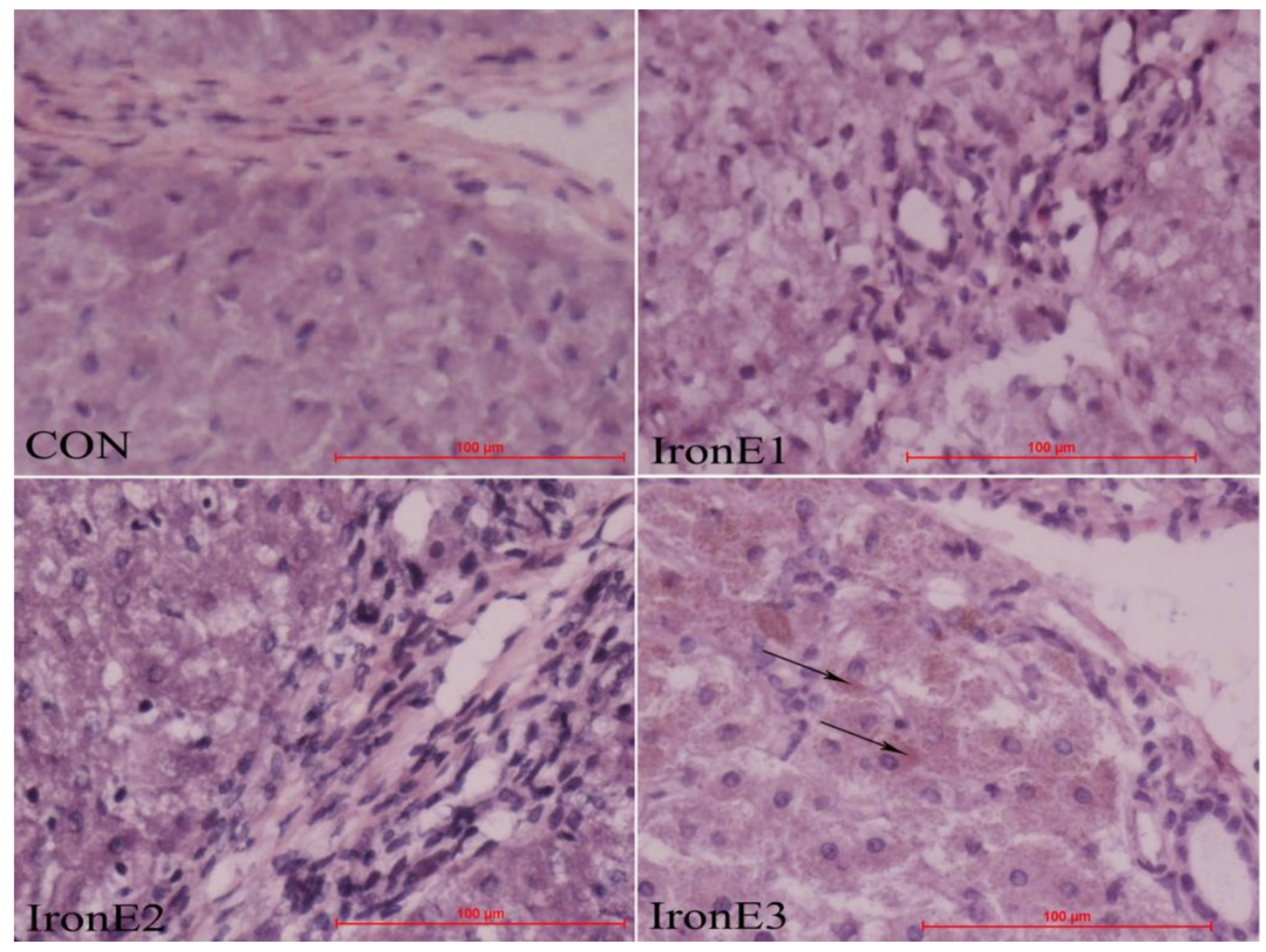

Figure 6

Histopathological disorders of liver with excess iron in sheep $(\mathrm{HE} \times 400)$ 


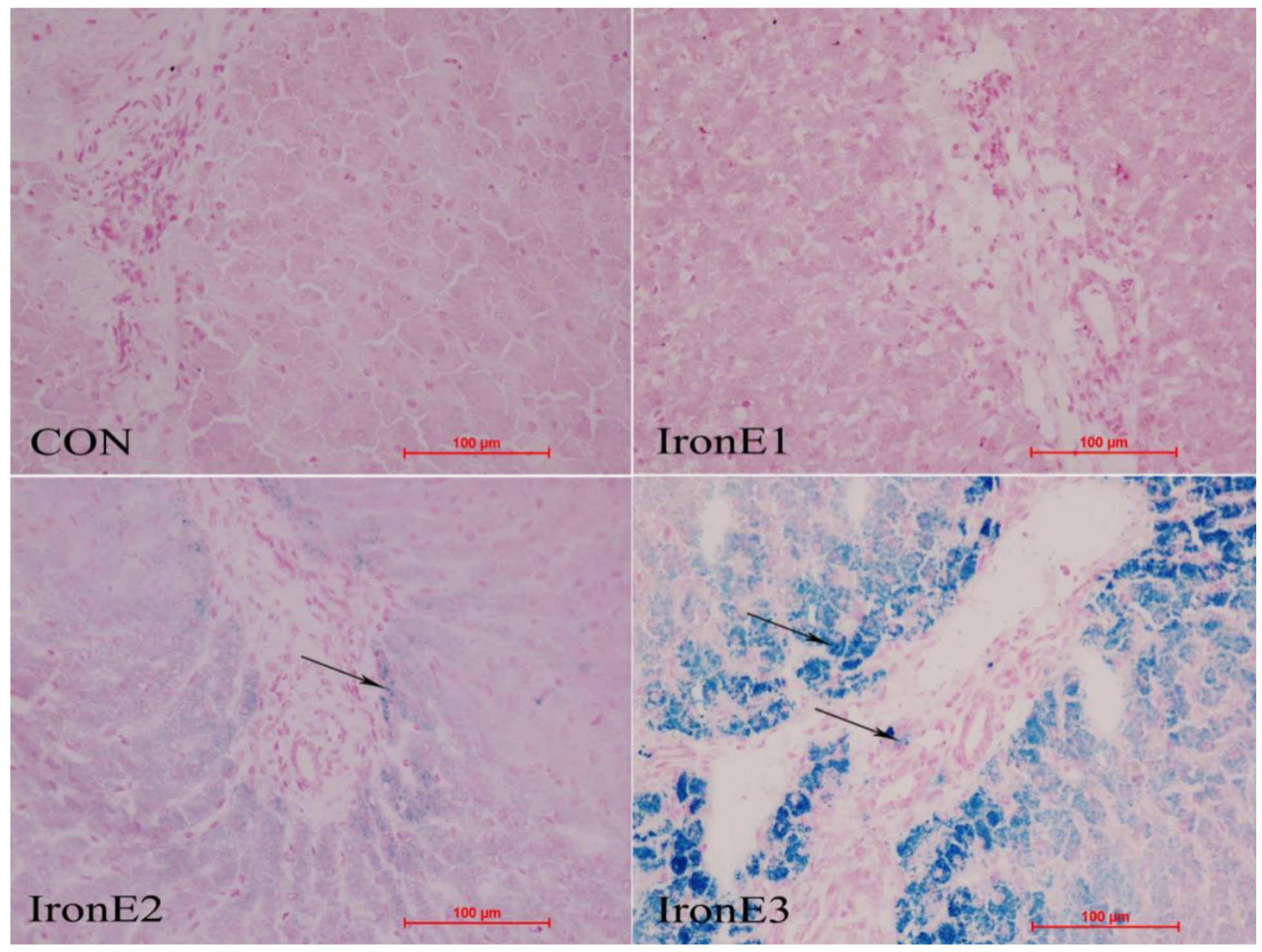

Figure 7

Distribution of iron deposits in liver with excess iron in sheep(Perl $\times 200)$ 